\title{
UTILIZAÇÃO DA TECNOLOGIA NA FORMAÇÃO SUPERIOR: AVALIANDO O PROGRAMA GEGOGEBRA
}

\author{
Lázzaro Henrique Soares Barbosa
}

\section{RESUMO}

O presente artigo discute as práticas pedagógicas a partir da utilização do GEOGEBRA no processo ensino aprendizagem, considerando a adesão e receptividade dos professores para tal. Busca-se aqui conhecer a realidade dos professores, identificar a sua formação e habilidades na área de tecnologia e a possibilidade de investir na formação docente, discutindo até que ponto 0 referido programa promove a aprendizagem e a renovação na práxis pedagógica dos professores na universidade e os possíveis entraves na sua utilização e de que forma esse contexto afeta o alunado. Obteve-se como referencial teórico as abordagens que melhor versam sobre a temática atualmente apontando para a necessidade de práticas pedagógicas que ajudem a dinamizar o ensino através da tecnologia.

Palavras-chave: Formação Docente. GEOGEBRA. Prática Pedagógica. Aprendizagem Tecnologias da Informação.

\section{ABSTRACT}

This article discusses pedagogical practices from the use of GEOGEBRA software in the teaching learning process, considering the support and receptivity of teachers for this. It seeks here to know the reality of teachers, to identify their training and skills in the area of technology and the possibility of investing in teacher training, discussing the extent to which this program promotes learning and renewal in the pedagogical praxis of teachers in the university and the possible obstacles in their use and how this context affects the student. The theoretical framework was obtained as the approaches that best deal with the 
theme currently pointing to the need for pedagogical practices that help to boost teaching through technology.

Keywords: Teacher Training. GEOGEBRA. Pedagogical Practice. Learning Information Technologies.

*Lázzaro Henrique Soares Barbosa é graduando do 7ํ. semestre de Engenharia Elétrica no Instituto Federal de Tecnologia da Bahia em Vitória da ConquistaBahia.

\section{INTRODUÇÃO}

Os avanços da tecnologia no século XX passam por uma popularização ainda que lenta ampliando as possibilidades de comunicação e informação com a televisão, o rádio, o jornal impresso. Os meios de comunicação de massa provocam as primeiras mudanças em torno de uma comunicação mais acessível. Com a chegada do computador e da internet já nos finais do século, essas possibilidades se ampliaram. A não-linearidade, a instantaneidade, a interatividade e a acessibilidade, se disseminaram, permitindo ao mundo, uma globalização de produtos.

Essa nova cultura abarcará um novo discurso de valores e modelos preconizados por uma concepção planetária online. A comunicação passa de uma perspectiva do mesmo tempo/ espaço para emissor/receptor para tomar um percurso diferente. Assim, como ocorreram nos séculos anteriores com as inovações tecnológicas, as massas continuaram alijadas desse novo processo.

E nesse espantoso progresso científico e tecnológico, as tecnologias de informação e comunicação passam por uma ressignificação, pois o ideal é a popularização, pois assim a disseminação de valores e a globalização terão condições de causar os impactos tão desejados, contudo, o campo educacional 
que deveriam apresentar-se como condição sine qua non para facultar todas as possibilidades e ampliação da tecnologia, dorme em mansas águas.

A tecnologia, aqui tomada como invenções, criações e descobertas, proporcionou uma mudança profunda nas relações sociais, culturais, políticas, educacionais, econômicas. Lentamente seus produtos foram chegando à educação. O uso da tecnologia na educação propõe alternativas para uma ação pedagógica mais dinâmica e que facilite a busca do conhecimento.

Os professores são estimulados para adotar o uso do computador em suas aulas como auxílio na construção do conhecimento para desenvolver no aluno a capacidade de interagir com o mundo e produzir o conhecimento com autonomia e criatividade. (DIAS, 2017).

Assim, na "era da informação", é imprescindível inserir e utilizar as ferramentas tecnológicas de informação e da comunicação no contexto educacional. O ensino agora, mais do que nunca, deve ocorrer de forma plural e não mais individualizada, na colaboração e na interação. Não se pode ignorar o novo e manter-se nas velhas práticas pedagógicas que às vezes não estimula os alunos a buscar o conhecimento. A prática pedagógica deve evoluir à medida que os espaços educacionais vão se renovando. (DIAS, 2017).

Nessa perspectiva, alguns programas e softwares foram sendo introduzidos na prática pedagógica e entre eles o programa GEOGEBRA, um produto livre e gratuito, podendo ser classificado como um Software de Geometria Dinâmica. Mais do que a análise do programa em si busca-se nesse artigo avaliar o preparo do profissional que usa o recurso em sala de aula e o alcance dessa prática na vida e cotidiano do aluno.

\section{GEOGEBRA, E SUA APLICABILIDADE}

De acordo com Silva e Penteado (2009) 
Entende-se por softwares de Geometria Dinâmica aqueles capazes de construir e manipular objetos geométricos na tela do computador. Além disso, o que diferencia um software de Geometria Dinâmica dos demais é a possibilidade de "arrastar" a figura construída utilizando o mouse. Esse procedimento permite a transformação da figura em tempo real (SILVA e PENTEADO, 2009, p. 4).

Constitui-se assim em um programa utilizado como recurso metodológico no processo de ensino e aprendizagem da Matemática, que pode ser aplicado a todos os níveis de ensino, através da álgebra, geometria, gráficos, tabelas, estatística, construções que se utilizam pontos, segmentos, retas, ângulos, vetores, cônicas, seções e funções.

O GEOGEBRA é um programa atribuído à construção de conceitos e objetos matemáticos. É uma ferramenta de estudo, que abrange tópicos de geometria, álgebra e cálculo. Apresenta relevantes contribuições pela dinâmica de sua funcionalidade. No quadro, que é estático, segundo CHICON et al, ( 2011), o professor apresenta dificuldades em desvelar correlações entre as incógnitas e suas correspondências no gráfico.

Com o GEOGEBRA a aula passa a ter em formato dinâmico, onde 0 educando visualiza a matemática em movimento. O professor debate em torno dos parâmetros ao movimentar o gráfico. $O$ receptor assim tem a possibilidade de perceber a matemática em sua essência. De acordo com os autores, o GEOGEBRA traz uma dimensão que sobrepõe o plano de visão e imaginário proposto pelos recursos propostos pela educação tradicional, quadro/giz e dos livros-textos, trazendo com a utilização dos seus recursos a ideia de movimento correspondente à ação dos coeficientes das funções, assim o educando pode observar o efeito gráfico e algébrico.

É uma ferramenta sem dúvida formidável se usada com proficiência e não há como negar os benefícios decorrentes dessa e de outros recursos das tecnologias para a vida dos homens, no seu convívio social e nas estruturas sociais, possibilitando novos conhecimentos, ampliação e alteração nas 
sociedades. Novos processos criativos podem ser potencializados pelos fluxos sócio-técnicos de ambientes virtuais de aprendizagens que utilizam o digital como suporte a exemplo, o ciberespaço, enfim essa série de recursos midiáticos que repercutem no meio educacional.

Novos desafios se impõem em termos de como processar a quantidade de informação que é veiculada, de entender como a educação é capaz de mediar esse processo, de como o uso das mídias pode garantir a aprendizagem e de como adequá-las ao ensino de maneira mensurada e inteligente.

Decerto as mudanças nos processos de trabalho exigem 0 desenvolvimento de habilidades metacognitivas e de competências para aprender a ser, aprender a cooperar, apoiadas em conteúdos contextualizados e na experiência individual, afinam-se com os propósitos da educação mediada por novas tecnologias. A educação tem experimentado mudanças na inserção de novas tecnologias nas escolas e universidades.

Muito se tem discutido sobre novas abordagens metodológicas a partir do uso das tecnologias digitais na educação como mediador do processo ensinoaprendizagem e, vários são os desafios que se colocam, sendo que o principal problema se converge quanto a sua utilização. A ingenuidade em acreditar que o ato de substituir o giz, o quadro, o caderno, pelo emprego das tecnologias de comunicação e informação irá assegurar o sucesso no processo ensinoaprendizagem, não procede, pois se a sua utilização não for planejada dentro de uma visão crítica reflexiva.

(...) são os meios, os apoios, as ferramentas que utilizamos para que os alunos aprendam. A forma como os organizamos em grupos, em salas, em outros espaços isso também é tecnologia. O giz que escreve na lousa é tecnologia de comunicação e uma boa organização da escrita facilita e muito a aprendizagem. A forma de olhar, de gesticular, de falar com os outros isso também é tecnologia. O livro, a revista e o jornal são tecnologias fundamentais para a gestão e para a aprendizagem e ainda não sabemos utilizá-las adequadamente. $O$ gravador, o retroprojetor, a televisão, o vídeo também são tecnologias importantes e também muito mal utilizadas, em geral (VIEIRA, 2003, p. 151). 
Conforme Vieira (2003) as velhas concepções de ensino aprendizagem assumirão uma faceta de um movimento de modernização conservadora. $O$ problema estará centralizado na prática pedagógica, apresentando múltiplas possibilidades, consolidada na ação e determinada na nas crenças do professor.

\section{CONCEPÇÃO DE APRENDIZAGEM E PRÁTICA PEDAGÓGICA}

Para que uma prática que observe efeitos pedagógicos esperados, é necessário, que se questione qual a concepção de ensino-aprendizagem adotada na instituição, seja ela de qualquer nível e/ou modalidade e, consequentemente, norteadora da prática do professor.

Moran (2007) lembra que atualmente, é preciso inventar um novo modelo de educação, já que se vive em uma época que favorece a oportunidade de disseminar vários modos de pensamento. Nada mais oportuno e pleno de possibilidades que expandir essas novas formas e novos pensares.

Assim o um novo estilo de pedagogia sustentado por uma modalidade comunicacional que supõe entre as pessoas e a máquina interatividade, participação, e multiplicidade de conexões entre informações. O essencial aqui não é somente a tecnologia, porque mais do que nunca, o professor está desafiado a modificar sua comunicação em sala de aula e na educação.

Isso significa modificar sua concepção e atuação enquanto docente e inventar um novo modelo de educação, antenada com a realidade que aí está digital, multiletrada e a ser encaminhada para uma estética plena. Se a tecnologia de comunicação e informação aí está e pressupõe numa nova abordagem para a instituição é preciso saber escolher, planejar, interpretar, sendo que o essencial é pensar num uso consciente.

O desenvolvimento de uma cultura informática é essencial na reestruturação da maneira como se dá a gestão da educação, a reformulação dos programas pedagógicos, a flexibilização das estruturas de ensino, a 
interdisciplinaridade dos conteúdos, o relacionamento dessas instituições com outras esferas sociais e com a comunidade como um todo. As novas oportunidades tecnológicas exigem transformações não apenas das teorias educacionais, mas na própria ação educativa e na forma como as instituições, e toda sociedade percebe a sua função na atualidade.

Esses aspectos de alteração e que reorientam o processo ensinoaprendizagem amplo para novas configurações, mostram-nos a necessidade de reorganização das políticas educacionais, da gestão e das formas de avaliação da Educação em se e não apenas as mudanças dos métodos pedagógicos e das disciplinas, a partir da utilização efetiva das redes no ensino escolar. Ou seja, as mais modernas tecnologias de informação e comunicação exigem uma reestruturação ampla dos objetivos de ensino e de aprendizagem e, principalmente, do sistema escolar como um todo.

O sistema educacional precisa pensar de forma sistemática sobre uma educação de qualidade e, a priori saber se esse uso é pautada numa visão crítica-reflexiva ou se a tecnologia digital estará sendo usada apenas como uma ferramenta numa perspectiva também tradicional, na medida que se torna imposta.

O uso por si só da tecnologia, não é garantia de sucesso, os recursos tecnológicos, midiáticos são uma ferramenta a auxiliar professor e aluno no fazer educacional e as tecnologias são oportunidades aproveitadas por ambos para impulsionar a educação de acordo com as necessidades sociais de cada época. As tecnologias se transformam, muitas caem em desuso, e as instituições permanecem.

A educação transforma suas ações, formas de interação entre as pessoas e transforma os conteúdos, mas é sempre essencial para viabilização de qualquer proposta de sociedade e nesse aspecto a tecnologia deve ser tida como um meio para o letramento e não como o fim dele. 
Assim, pensar na principal função da Universidade, enquanto formadora de sujeitos sociais leitores da própria realidade e capazes de usar a escrita como instrumento indispensável à sua participação na construção histórico e cultural, implica garantir uma ação educacional voltada para o desenvolvimento da competência comunicativa do aluno, da sua capacidade de interpretar/produzir construções simbólicas, para que ele se torne capaz de ler e pronunciar o mundo.

Para tanto, é imprescindível que a ação pedagógica se desenvolva segundo uma prática que contemple a utilização de materiais escritos diversificados, ou seja, os materiais de apoio pedagógico devem constituir-se não apenas do livro didático, mas, sobretudo dos diferentes textos que circulam socialmente.

É latente o estudo e entendimento dessas diversas abordagens para que a prática seja norteada de maneira responsável, equilibrada e eficaz no objetivo último que é a aprendizagem. O fator que mais chama a atenção é a insuficiência do preparo técnico frente à multiplicidade de informações que os alunos trazem do seu cotidiano e de sua história de vida.

As instituições têm papel fundamental na construção da identidade e da autonomia de cada aluno. Por isso, no nosso entender, é primordial trabalhar não apenas leitura, mas todas as leituras que se apresentam no nosso dia a dia. Nas escolas em que circulam diversos tipos de textos, os alunos leem e escrevem mais rapidamente e se tornam capazes de buscar as informações de que necessitam.

O indivíduo é um ser interativo, pois seus conhecimentos se estabelecem a partir das relações interpessoais e intrapessoais, ou seja, é um processo que se dá de fora para dentro. Desse modo, o ser humano se apropria de conhecimentos através da interseção entre aspectos da história pessoal e social. É nesse processo de ensino-aprendizagem que ocorre a apropriação da cultura e o consequente desenvolvimento do indivíduo. 
Historicamente, a tecnologia é a quarta e última revolução do ensino que está se dando com o advento das tecnologias da informação e comunicação, em que as instituições escolares ainda estão em processo de adaptação e incorporação das novas tecnologias. No entanto, este processo, que teve início, no Brasil, a partir da década de 90, ainda se apresenta como uma dificuldade para alunos e professores, que, muitas vezes, enxergam a tecnologia como um instrumento de difícil utilização. Dentre várias tentativas de se levar a inclusão aos alunos, podemos colocar as salas de laboratórios de informática e os telecentros. (DIAS, 2017).

Naquele momento, para estar incluído digitalmente, bastaria ter acesso ao computador, na contemporaneidade, além do manuseio, o usuário deveria produzir conhecimento e transformar sua a vida a partir deste. O foco agora é o que os indivíduos fazem com as tecnologias, se as utilizam construindo conhecimentos significativos. (DIAS, 2017).

Assim, não se pode negar que o computador na sala de aula beneficia a cultura digital, pois admite aos educandos explorar a inteligência coletiva, conhecendo e interagindo com várias culturas, descobrindo outras linguagens, construindo e reconstruindo saberes sem estar inertes em sala de aula.Usar o computador no desenvolvimento de uma aula não quer dizer fazer a integração delas. Isso vai além de usar um recurso tecnológico como complemento de uma atividade. (DIAS, 2017).

A utilização da tecnologia deve estar presente na educação, sistematizada de acordo com o processo histórico social, como a utilização do giz e da lousa, claro que, ainda hoje, utilizada em muitas escolas; bem como o livro didático ainda usado na era da informação e do conhecimento, o que se torna um desafio do mundo contemporâneo.

Adaptar a educação à tecnologia moderna e aos meios de comunicação eletrônicos não garante o bom resultado educacional, mas é necessária a adaptação do ensino e aprendizagem ao uso dos principais produtos tecnológicos, uma vez que os equipamentos chegam às escolas públicas. 
$\mathrm{Na}$ sociedade da informação todos estão reaprendendo a conhecer, a comunicar-nos, a ensinar e a aprender; a integrar o humano e o tecnológico; a integrar o individual, o grupal e o social. Uma mudança qualitativa no processo de ensino/aprendizagem acontece quando conseguimos integrar dentro de uma visão inovadora todas as tecnologias: as telemáticas, as audiovisuais, as textuais, as orais, musicais, lúdicas e corporais. Passamos muito rapidamente do livro para a televisão e vídeo e destes para o computador e a Internet, sem aprender e explorar todas as possibilidades de cada meio. (MORAN, 2000, p. 01).

Não é simples utilizar as tecnologias como estratégia eficaz no processo de mudança na educação, principalmente, se não houver formação para os profissionais e espaço para um novo olhar sobre a relação do conhecimento com o ensinar e aprender.

Com o computador em mãos, os alunos se aventuram, se arriscam, fazem descobertas, criam hipóteses, isso é estimulante e torna o aprendizado significativo, bem diferente do que é proposto, na maioria das vezes, em sala de aula. A informática dá oportunidades ao aluno de adquirir novos conhecimentos, facilitar o processo ensino aprendizagem, enfim, sem um complemento de conteúdos curriculares, visando o crescimento integral do indivíduo.

Moran (2000) enfatiza a importância do uso de novas tecnologias nas salas de aula como alternativa de ensino frente a uma sociedade mediada por aparelhos eletrônicos, mas ressalta a importância de se discutir os conteúdos transmitidos nesses meios de comunicação, interação com a sociedade e a realidade do estudante $A$ escola, ao fazer uso das tecnologias, e em destaque 0 computador, permitiu a ampliação de oportunidades para novas concepções, métodos de ensino, possibilitando uma aprendizagem articulada e contextualizada a realidade do aluno.

Há que se ter clareza do que isso está significando, para além da surpresa no primeiro momento ou por ser uma novidade do ponto de vista pedagógico. Há 
que se questionar: $O$ professor tem habilidades e competências no uso da tecnologia para garantir o cumprimento do currículo? A simples presença dos laboratórios de informática muda à realidade da instituição? Alguns questionamentos são lançados na busca de resposta que possa garantir o conhecimento e uma aprendizagem significativa com o uso de novas tecnologias e ferramentas em sala de aula.

Infelizmente o que se mantém na Universidade são as velhas práticas, atreladas ainda ao ensino tradicional, obsoleto que exclui de certa forma as tecnologias, sem entendê-las como facilitadoras do processo de ensino e também do trabalho do professor. Como ferramenta ou como recurso pedagógico, o uso das tecnologias pode e deve ser de grande valia em qualquer sala de aula. Seja no ensino médio onde os alunos estão se movimentando para iniciar no mercado de trabalho ou na educação infantil onde nossas crianças atuais já nasceram na era digital e seja na Universidade onde estão às portas do mercado de trabalho.

Esse apego a velhas práticas pode estar atrelado a formação insuficiente à demanda necessária para que esses docentes utilizem a tecnologia como ferramenta de trabalho, pois outras dificuldades se fazem presentes, mas podem também ser frutos do ambiente inadequado para tal utilização, como também o próprio comodismo em receber o novo.

De acordo com Moran (2003, p.12): "um dos grandes marcos do mundo contemporâneo é o fenômeno da mudança". No entanto, essa mudança gera resistência e assim um novo desafio surge: conscientizar os profissionais envolvidos da importância da mudança de modo que se sintam estimulados e se tornem capazes de ir além dos seus próprios limites.

O professor precisa entender que embora pareça algo distante, as TIC já fazem parte do cotidiano, seja através do computador, da televisão, dos jornais, revistas, panfletos, propagandas, revistas em quadrinhos, celular. Muitas são as formas de tecnologia e comunicação às quais nem percebemos e que podem 
ser utilizadas como meios ou ferramentas de auxilio no processo de ensinoaprendizagem sem que seja criada uma disciplina para tal.

A ferramenta GEOGEBRA pode e deve ser utilizada como recurso de ensino que facilita a vida tanto do professor quanto do aluno e sua eficácia e eficiência se mostram comprovadas por todos que dela fazem uso.

\section{CONSIDERAÇÔES FINAIS}

Não se pode ignorar a importância do computador e dos programas e softwares no processo de ensino aprendizagem. Fazer isso é usurpar o direito dos alunos de usufruir de práticas que acontecem no meio social, as informações e comunicação oferecidas pela sociedade por diversos aparelhos eletrônicos que são utilizados no contexto atual.

A exclusão tecnológica, compete em descaracterizar o papel das instituições em desenvolver saberes que serão utilizados do cotidiano do indivíduo. A tecnologia torna-se instrumento fundamental na inserção social, mesmo sendo acessível para grupos sociais minoritários ou excluídos que necessitam ampliar seu conhecimento.

A escola o Universidade em condições apropriadas aliada à tecnologia oferece aos alunos difusão dos seus conhecimentos através do laboratório de informática e com os recursos que gerem benefício individual e coletivo de maneira a garantir que todos os estudantes universitários tenham acesso. $O$ programa GEOGEBRA é certamente uma dessas ferramentas que visam possibilitar, inserção, aprendizagem significativa e celeridade no processo ensino-aprendizagem também para o professor.

Nesse contexto de tecnologias educacionais, o papel do educador também deve ser redimensionado, não mais como transmissor de informações 
prontas e acabado, mas de agente dinamizador e orientador na construção do conhecimento, apontando ao aluno a necessidade crítica e ativa em relação às informações ao qual o aluno é submetido diariamente.

Outrossim, a construção do conhecimento passa a ser criativa, dinâmica, emocional, intelectual, complexa e desafiadora no novo cenário de ação pedagógica. Isso implica, trabalhar com o princípio do ensino-aprendizagem duplo e, assim, na relação professor-aluno-conhecimento presente na interatividade como requisito de construção do conhecimento. 


\section{REFERÊNCIAS}

CHICON, Thays Roberta; FERNANDES, Ivania Maria librelotto; LIMA, Cláudia Santos; MELO, Maria Christina Shettert; NEDEL, Vera Lúcia; WILSMANN, Leomir. Geogebra e o Estudo da Função Quadrática. Parada Benito: UNICRUZUniversidade de Cruz Alta, 2011. Disponível em: <http://www.unicruz.edu.br/16_seminario/artigos/agrarias/GEOGEBRA\%20E\%2 00\%20E STUDO\%20DA\%20FUNÇÃO\%20QUADRÁTICA.pdf>. Acesso em: 20 fevereiro de 2018.

DIAS. Leliam B. S. O PROINFO e as práticas pedagógicas no Laboratório de informática. (2017). Disponível em http://www.minerva.edu.py/archivo/8/2/ARTIGO\%20LELIAM.pdf. Acesso em março de 2020.

MORAN, José Manuel, MASETTO, Marcos e BEHRENS, Marilda. Novas Tecnologias e Mediação Pedagógica. São Paulo, Papirus Editora, 2000. Publicado em Educacional. Disponível em:

www.ufpel.edu.br/crm/pgl/computador/ensino tecnologias.doc. Acesso em 23 de fevereiro de 2020.

SILVA, G. H. G \& Penteado, M. G. (2009). O trabalho com Geometria dinâmica em uma perspectiva investigativa. Recuperado de http://www.pg.utfpr.edu.br/sinect/anais/artigos/10\%20Ensinodematematica/Ensi nodemate matica artigo17.pdf. Acesso em fevereiro de 2020.

VALENTE, J. A. Visão analítica da Informática na Educação no Brasil: a questão da formação do professor. Revista Brasileira de Informática na Educação. RS: Sociedade Brasileira de Computação, no 1, set. de 1999.

Repensar as situações de aprendizagem: o fazer e o compreender. Série "Tecnologia e Educação: Novos tempos, outros rumos" - Programa Salto para o Futuro, Setembro, 2002. Acessado em 21 de novembro de 2015.

O computador na sociedade do conhecimento. Organizador UNICAMP/NIED; Campinas, SP: 1999. 
Visão analítica da informática na educação do Brasil: a questão da formação do professor. Revista Brasileira de informática na Educação. Da Sociedade Brasileira de Computação, № 1, setembro p. 45-60 